Proceedings of the Operational Research Society Simulation Workshop 2021 (SW21)

M. Fakhimi, D. Robertson, and T. Boness, eds.

DOI: https://doi.org/10.36819/SW21.005

\title{
A TUTORIAL ON INVOLVING STAKEHOLDERS IN FACILITATED SIMULATION STUDIES
}

\author{
Kathy Kotiadis \\ Kent Business School \\ University of Kent \\ Canterbury, Kent, CT2 7NZ UK
}

\author{
Antuela A.Tako \\ School of Business and Economics \\ Loughborough University \\ Leicestershire, LE11 3TU, UK
}

\begin{abstract}
This tutorial introduces the PartiSim approach, aimed at supporting analysts and simulation modellers to carry out facilitated discrete event simulation studies. Facilitated simulation offers an alternative mode of engagement with stakeholders (clients) in simulation projects. It is particularly beneficial when modelling systems with complex behaviour, involving many stakeholders with plurality of opinions and objectives. PartiSim short for Participative Simulation, is a facilitated modelling approach developed to support simulation projects through a framework, stakeholder-oriented tools and manuals in facilitated workshops. A PartiSim study includes six stages, four of which involve facilitated workshops. PartiSim was developed more than 10 years ago. It can be applied to analyse operational problems in many contexts within the services and manufacturing domain. This tutorial presents the PartiSim framework and tools, some applications and example tools, a roadmap to adopting it and concludes with some tips for potential users.
\end{abstract}

\section{INTRODUCTION}

This tutorial describes the PartiSim approach to analysts and simulation modellers. PartiSim short for Participative Simulation, is a facilitated modelling approach developed to support analysts in involving stakeholders in the modelling process in a non-technical way. Stakeholders are engaged primarily in facilitated workshops to identify options and consider solutions through the use of simulation models. The approach was developed as part of a project funded by the UK's EPSRC back in 2007. PartiSim consists of a framework (Tako and Kotiadis 2015), tools and manuals (Kotiadis et al 2014, Kotiadis and Tako 2018) that support the analyst in carrying out modelling activities involving stakeholders throughout the project. Its framework, tools and manuals were developed and tested in two UK healthcare settings in the UK. Subsequently a toolbkit was developed including a user guide, tools and manuals in 2010 (Kotiadis and Tako 2010), which was updated in 2018. These are available for modellers to download for free from the PartiSim website (www.partisim.org).

The authors have trained modellers on using PartiSim, mainly in the UK through the UK OR society training programme and to the best of our knowledge it has been embedded on at least two occasions in the curriculum of an undergraduate business and a postgraduate engineering module at two UK institutions. Further applications have followed, three of which we are aware of and two are from different teams of analysts, who report in the academic literature on its use. For example, Proudlove et al (2017) report using a similar approach to PartiSim to undertake facilitated modelling in three health care projects. Philips (2017) used PartiSim to explore uncertainty and production smoothing in a complex pharmaceutical manufacturing environment. It was furthermore applied in a healthcare ambulance setting as part of a masters dissertation project (Puntambekar, 2016) under the supervision of one of the coauthors (Tako). The success of these studies varies, however, they all identify the benefit of engaging the stakeholders in conversations to co-develop options and solutions for their own problems. 


\section{Tako and Kotiadis}

More specifically using the PartiSim approach, tools and guidance available (Kotiadis and Tako 2010) the modelling team can benefit, not only because the activities set out can help the modelling team to make sense of the complexities involved in their settings, but also because it allows the modelling team to engage concurrently with all the stakeholders leading to common views and consensus being built in a transparent way at one meeting (workshop). It furthermore allows for the stakeholders to be part of the process and the solutions identified, while at the same time non-technical language is used to extract their views. The dedicated tools supporting each workshop allows for a more structured and leaner modelling process throughout the study, compared to studies where the modeller is developing the model on his own and checks or validates the model with individual stakeholders on a one to one basis. The suggestions and tips available in the tools and manuals for the facilitator to use enable better communication with the stakeholder group rather than making up the questions on the spot. Undertaking the simulation study in a participative way can help save time in building the model on the computer, mainly because the workshops enable a common understanding between the modeller and stakeholder team on what should be included in the model, as well as commitment and quick access to the data needed to develop the model.

Based on our experience of developing and using the PartiSim framework, this tutorial aims to guide the analyst in using the PartiSim framework and tools in their participative simulation studies. Section 2 provides an overview of the PartiSim framework, including the activities and tools used to support each stage of the simulation study. Section 3 illustrates applications of PartiSim in real life studies, based on our experience of using it and discusses the outcomes of these studies. Section 4 introduces three example tools used in PartiSim workshops to give modellers an insight of how they are used in practice. Section 5 provides a roadmap of the journey that the modelling team should take at an individual and team level in adopting the approach. Section 6 concludes this tutorial with some practical tips for using the PartiSim approach and its tools for potential adopters.

\section{OVERVIEW OF THE PARTISIM FRAMEWORK \& TOOLS}

The PartiSim approach is designed to support the modellers' interaction with a group of stakeholders throughout the DES study lifecycle. A framework and tools support the modeller in undertaking the different modelling activities during a simulation study. The framework, outlined in Table 1, consists of six key stages and/or five sub-stages (column 1); each includes a number of prescribed activities (column 2), tools (column 3) and corresponding stakeholder-oriented deliverables (outputs) (column 4), which enable participative DES modelling to take place.

The main PartiSim stages include: 1. Initiate simulation study; 2. Define Problem; 3. Define conceptual model; 4. Model Coding; 5. Experiment with model; 6. Implement Findings (Tako and Kotiadis 2015, Kotiadis and Tako 2010). The sub-stages support the main stages, either to prepare for the workshop-based stages or to tidy up outputs developed in workshops and confirm these with the stakeholders. Model coding, a middle stage in PartiSim, is not undertaken in a facilitated mode and that is acceptable practice in facilitated DES (Robinson et al 2014).

The aims of each stage (and sub-stage) are achieved by undertaking the prescribed dedicated activities (Table 1, column 2), which are distinguished in two types: modelling and workshop activities. The modelling activities are aimed at supporting the modelling process while workshop activities support the facilitation of the group of stakeholders. The activities for the sub-stages are mainly undertaken by the modelling team, who report back to the stakeholders the outputs agreed in the workshops or seek further reflections and clarifications. Some activities such as those undertaken in stage 1 and mostly in the substages are generic in nature and related mainly to organising the simulation project or liaising with the stakeholder team. They could be used in any type of analysis carried out in a facilitated mode. Other activities are adapted or borrowed from Soft Systems Methodology (Checkland 1999). For example, the activity "Define system \& boundaries" (stage 2), involves decomposing the system into the activities that take place in that system. Traditional DES modelling activities are adapted to be carried out in a facilitated environment, giving stakeholders the space to express their preferences and discuss 


\section{Tako and Kotiadis}

alternatives. For example in the "Debate desirable and feasible solution space" activity (stage 5) the results of relevant scenarios are presented and debated with the stakeholders.

Each stage is supported by tools and the associated manuals which support the modelling team and stakeholders to reach to the prescribed dedicated outputs for each stage (column 3, Table 1). Scripts are also available for some of the stages, aimed mainly at the facilitator. These are different from the tools or manuals in that they include advice to support the facilitation process for activities that do not require any specific tools to be used. These are paper based and freely available on the PartiSim website (www.partisim.org).

Most of the activities support the development of the intermediate deliverables or outputs (Table 1, column 4). They are called intermediate because they can be revised or converted into a different output in the next stage. Some, for example "A bounded system within which the problem to be addressed exists" (sub-stage 2.a), are developed in a sub-stage with the view to using and leading the discussion during the workshop in stage 3 . While others such as the conceptual model (stages 2 and 3), are developed during the workshop, but refined during a sub-stage (3.a) and converted into a different output (a simulation model) in stage 4.

Table 1: The PartiSim Framework, including stages, activities, tools and outputs

\begin{tabular}{|c|c|c|c|}
\hline Stage \& purpose & Activities $^{1}$ & Tools & Outputs \\
\hline $\begin{array}{l}\text { 1. Initiate Study } \\
\text { Purpose: } \\
\text { Identify stakeholder } \\
\text { team } \\
\text { Identify key problem } \\
\text { situation(s) }\end{array}$ & $\begin{array}{l}\text { The modelling team undertake: } \\
\text { - informal meetings and/or } \\
\text { - on-site observations and/or } \\
\text { - one-to-one interviews } \\
\text { - with project champion and } \\
\text { key stakeholder(s), to address } \\
\text { preliminary information } \\
\text { needs }\end{array}$ & $\begin{array}{ll}- & \text { Feasibility of } \\
\text { simulation modelling } \\
\text { and its use Script } \\
-\quad \text { Situation of Interest } \\
\text { Tool with manual } \\
-\quad \text { Recording } \\
\text { Observations Tool } \\
\text { with manual } \\
\text { - } \quad \text { Bank of questions } \\
\text { Script } \\
\text { - Stakeholder details } \\
\text { Tool with manual } \\
-\quad \text { List of reading } \\
\text { materials Tool with } \\
\text { manual }\end{array}$ & \multirow[t]{2}{*}{$\begin{array}{l}\text { List of stakeholder } \\
\text { team roles. } \\
\text { Preliminary } \\
\text { understanding of the } \\
\text { problem situation } \\
\text { Study proposal, incl. } \\
\text { initial study aims and } \\
\text { timescales }\end{array}$} \\
\hline $\begin{array}{l}\text { 1.a Pre-workshop } \\
\text { (Sub-stage) } \\
\text { Purpose: } \\
\text { Preparations for } \\
\text { workshop } 1\end{array}$ & $\begin{array}{l}\text { - Identify modelling team and } \\
\text { stakeholder team roles. } \\
\text { - Modelling team prepare } \\
\text { preliminary materials to be } \\
\text { used in workshop } 1 \\
\text { - Decide workshop venue and } \\
\text { time slots. } \\
\text { - Stakeholders are invited to } \\
\text { workshops }\end{array}$ & & \\
\hline $\begin{array}{l}\text { 2: Define the } \\
\text { Problem (workshop } \\
\text { 1) } \\
\text { Purpose: } \\
\text { Agree on the } \\
\text { problem situation } \\
\text { and the wider } \\
\text { system, within which } \\
\text { it exists. }\end{array}$ & $\begin{array}{l}\text { Agree problem statement } \\
\text { Define the system } \\
\text { Draw a system model }\end{array}$ & 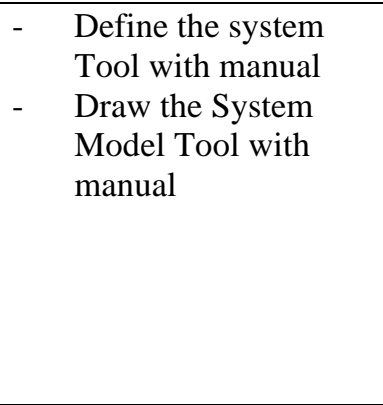 & $\begin{array}{l}\text { Overall study } \\
\text { objectives/aims } \\
\text { System map }\end{array}$ \\
\hline
\end{tabular}


Tako and Kotiadis

\begin{tabular}{|c|c|c|c|}
\hline $\begin{array}{l}\text { 2.a Post } \\
\text { workshop1/Pre- } \\
\text { workshop } 2 \text { stage } \\
\text { Purpose: } \\
\text { Disseminate } \\
\text { workshop } 1 \text { outputs } \\
\text { and prepare for } \\
\text { workshop } 2\end{array}$ & $\begin{array}{l}\text { Modelling team re-draw tools \& } \\
\text { disseminate workshop outputs } \\
\text { to stakeholders } \\
\text { Prepare preliminary materials } \\
\text { for use in workshop } 2\end{array}$ & & \\
\hline $\begin{array}{l}\text { 3. Define conceptual } \\
\text { model (workshop 2) } \\
\text { Purpose: } \\
\text { Define specific } \\
\text { elements of the } \\
\text { conceptual model }\end{array}$ & $\begin{array}{l}\text { Participating stakeholders take } \\
\text { part in a facilitated workshop } \\
\text { process to: } \\
\text { - Brainstorm study objectives } \\
\text { - Draw the Performance } \\
\text { Measurement Model (PMM) } \\
\text { - Define simulation study } \\
\text { objectives } \\
\text { - Draw communicative model } \\
\text { - Discuss data collection }\end{array}$ & $\begin{array}{l}\text { - } \begin{array}{l}\text { Performance } \\
\text { Measurement Model } \\
\text { (PMM) with manual }\end{array} \\
\text { - } \quad \begin{array}{l}\text { Study objectives } \\
\text { Tool with manual }\end{array} \\
\text { - } \begin{array}{l}\text { Communicative } \\
\text { Model Tool with } \\
\text { manual2018 }\end{array}\end{array}$ & \multirow[t]{2}{*}{$\begin{array}{l}\text { Model inputs, outputs } \\
\text { and contents } \\
\text { Simulation objectives } \\
\text { Process flow diagram } \\
\text { A list of data } \\
\text { requirements }\end{array}$} \\
\hline $\begin{array}{l}\text { 3.a Post workshop } 2 \\
\text { (sub-stage) } \\
\text { Purpose: } \\
\text { Disseminate } \\
\text { workshop } 2 \text { outputs } \\
\text { and refine conceptual } \\
\text { model }\end{array}$ & $\begin{array}{l}\text { Modelling team: } \\
\text { - Prepare report detailing } \\
\text { Refined workshop outputs } \\
\text { and Data requirements } \\
\text { - Liaise with the stakeholder } \\
\text { team over correctness of } \\
\text { workshop } 2 \text { outputs. }\end{array}$ & & \\
\hline $\begin{array}{l}\text { 4. Model coding } \\
\text { Purpose: } \\
\text { Conceptual model is } \\
\text { converted into a } \\
\text { computer model }\end{array}$ & $\begin{array}{l}\text { - Data collection (modeller and } \\
\text { stakeholders) } \\
\text { - Build simulation model on } \\
\text { the computer (modeller) }\end{array}$ & & Model results \\
\hline $\begin{array}{l}\text { 4.a Pre-workshop } 3 \\
\text { sub-stage } \\
\text { Purpose: } \\
\text { Preparations for } \\
\text { Workshop } 3\end{array}$ & $\begin{array}{l}\text { - Prepare preliminary materials } \\
\text { for use in workshop } 3 \text { (stage } \\
\text { 5): } \\
\text { - Liaise with the project } \\
\text { champion over correctness } \\
\text { of model \& its results } \\
\text { (modeller and project } \\
\text { champion) } \\
\text { - Review preliminary } \\
\text { scenarios with project } \\
\text { champion } \\
\text { - Prepare preliminary } \\
\text { materials for use in the } \\
\text { next workshop }\end{array}$ & & $\begin{array}{l}\text { Model validation and } \\
\text { verification } \\
\text { Preliminary future } \\
\text { scenarios }\end{array}$ \\
\hline $\begin{array}{l}\text { 5. Experimentation } \\
\text { stage (workshop 3) } \\
\text { Purpose: } \\
\text { Define alternative }\end{array}$ & $\begin{array}{l}\text { Stakeholders are invited to: } \\
\text { - Validate the simulation model } \\
\text { \& its results } \\
\text { - Rate performance measures } \\
\text { (linked to model results) }\end{array}$ & $\begin{array}{ll}- & \text { Model validation } \\
\text { tool } \\
\text { - } & \text { Rating the } \\
\text { Performance } \\
\text { Measures tool (or }\end{array}$ & $\begin{array}{l}\text { Model validation and } \\
\text { verification } \\
\text { Alternative future } \\
\text { scenarios }\end{array}$ \\
\hline
\end{tabular}


Tako and Kotiadis

\begin{tabular}{|c|c|c|c|}
\hline $\begin{array}{l}\text { scenarios to } \\
\text { experiment with } \\
\text { model }\end{array}$ & $\begin{array}{l}\text { - Debate desirable and feasible } \\
\text { scenarios }\end{array}$ & $\begin{array}{l}\text { VISA) with manual } \\
\text { - } \quad \text { Debating the } \\
\text { Alternative } \\
\text { Scenarios tool with } \\
\text { manual }\end{array}$ & \\
\hline $\begin{array}{l}\text { 5.a Post-workshop 3/ } \\
\text { Pre-workshop } 4 \text { sub- } \\
\text { stage } \\
\text { Purpose: } \\
\text { Refine alternative } \\
\text { scenarios \& prepare } \\
\text { for workshop } 4\end{array}$ & $\begin{array}{l}\text { Modelling team: } \\
\text { - Tweak or correct simulation } \\
\text { model } \\
\text { - Implement additional } \\
\text { scenarios suggested (based on } \\
\text { stakeholder feedback from } \\
\text { workshop 3.) } \\
\text { - Liaise with the stakeholder } \\
\text { team over correctness of model } \\
\text { results } \\
\text { - Prepare preliminary materials } \\
\text { for use in workshop } 4\end{array}$ & & $\begin{array}{l}\text { New alternative future } \\
\text { scenarios } \\
\text { Revised simulation } \\
\text { model } \\
\text { Revised model results }\end{array}$ \\
\hline $\begin{array}{l}\text { 6. Implementation } \\
\text { stage (workshop 4) } \\
\text { Purpose: } \\
\text { Define an } \\
\text { implementation plan }\end{array}$ & $\begin{array}{l}\text { Stakeholders are invited to: } \\
\text { - Review learning \& changes } \\
\text { implemented } \\
\text { - Risk analysis and feasibility of } \\
\text { change } \\
\text { - Agree action trail }\end{array}$ & $\begin{array}{ll}\text { - } & \begin{array}{l}\text { Script for } \\
\text { Identifying changes } \\
\text { in the system }\end{array} \\
\text { - } & \begin{array}{l}\text { Feasibility and Risks } \\
\text { Scale tool with } \\
\text { manual }\end{array} \\
\text { - } & \begin{array}{l}\text { Barriers to Change } \\
\text { tool with manual }\end{array} \\
\text { - } & \begin{array}{l}\text { Action and } \\
\text { Communication } \\
\text { Plan tool with } \\
\text { manual }\end{array}\end{array}$ & $\begin{array}{l}\text { Agreeable and feasible } \\
\text { scenario(s) to be taken } \\
\text { forward } \\
\text { Action plan with } \\
\text { deliverables (including } \\
\text { due date and person } \\
\text { responsible) }\end{array}$ \\
\hline
\end{tabular}

${ }^{1}$ Activities in italics are workshop activities

\section{APPLICATIONS OF PARTISIM}

In this section we refer to some real life applications in which the PartiSim framework and tools have been used in practice. All three applications happen to be in health care in light of the authors' industry contacts and opportunities for collaboration. These are the Obesity (Tako et al 2014), Colorectal and Ambulance Service study. As noted in the introduction, there are more adaptations of PartiSim by other teams, however we concentrate here on the studies we have had direct experience with. A brief summary of each study follows.

The obesity study involved a newly set up service that provides services for London and Northern Ireland, offering three types of treatments: lifestyle treatment (i.e. advice on diet, exercise and behavioural change), pharmacotherapy (administration and management of weight loss medication) and bariatric surgery (also known as obesity surgery). The later involved three main types of surgery: gastric band, sleeve gastrectomy and gastric bypass. The service providers wanted to understand how to configure their resources (i.e. surgeons and physicians) in order to consistently meet the 18 week target in the foreseeable future, without adding unnecessary capacity, by employing new resources such as surgeons and physicians. At the time of the study (2009), the service was experiencing increasing numbers of referrals and an increased pressure to meet the demand for consultation and treatment. The pressure was mostly experienced in the parts of the system providing pharmacotherapy treatment and surgery. The service 


\section{Tako and Kotiadis}

referrals were increasing each year at an exponential rate which made planning difficult. For more details see Tako et al (2014).

The Colorectal study involved an outpatients surgical care service at a UK NHS Hospital which at the time (2009) had been experiencing increased demand for its clinics due to a then recently launched bowel screening programme. In addition, stakeholders believed that some patient categories, particularly those categorised as less urgent may have excessive waits during their journey along the colorectal cancer care pathway. The surgical service was offering out-of-hours outpatient clinics and colonoscopy tests in order to meet the increased demand and reduce the proportion of patients breeching waiting time targets. The stakeholders were interested to gain a better understanding of the demand for services and the existing levels of resource available i.e. staffed time for clinic appointments, colonoscopy examinations and surgery. The study explored the impact of introducing improvements to the colorectal pathway through a combination of re-organising and/or increasing the levels of some resources (e.g. clinic slots) on the performance of the clinic in terms of the size of the waiting lists and the proportion of patients breaching Department of Health targets ( 2 week, 18 week etc). The Obesity and Colorectal study were undertaken at the time of developing the PartiSim approach on a pro-bono basis, with the view to testing the tools and process.

The Ambulance Service (AS) study involved an NHS ambulance service Trust that provides prehospital emergency and urgent care services and patient transport to a specific local area population (Puntambekar, 2016). As with all UK's NHS services, this particular AS faced high demand levels for its services especially in the winter months, which in turn increases the pressure on the service to deliver safe care to patients within the required response time targets. At the time of the study (2016), the specific service was interested in improving the efficiency of its call cycle by reducing its overall call cycle times and the number of patients conveyed to emergency departments when not needed. Policies such as providing advice over the phone (hear and treat), treating patients at the scene (see and treat) and taking patients to alternative non-hospital destinations, such as urgent care centres, were being introduced and the service was keen to understand the impact of these changes on the AS performance. Clinical advisors had been hired by the AS Trust to provide Hear and Tread services over the phone to patients. In order to deliver valued analytical support to the AS a facilitated modelling approach was undertaken involving stakeholders from the AS throughout the study. The project was undertaken as a masters consultancy project on a pro-bono basis and one of the authors supervised the project and facilitated the workshops (Puntambekar, 2016).

All three studies followed the same PartiSim process and tools. The first two were used as case studies to test the tools developed, whereas the last was utilised by a novice modeller (masters student) to provide consultancy services as part of the summer project. The models developed represent mainly queuing systems of patients (or patient calls), which were amenable to modelling using a discrete-event simulation approach. Due to space limitations the models developed are not provided in this paper, however these were presented to and discussed with the relevant stakeholder teams. A summary of the key characteristics of these studies can be found in table 2 below.

Table 2: A summary of the key characteristics of the Obesity, Colorectal and Ambulance Service studies.

\begin{tabular}{|l|l|l|l|}
\hline & Obesity study & Colorectal study & Ambulance service study \\
\hline $\begin{array}{l}\text { Stakeholder } \\
\text { participation }\end{array}$ & Multidisciplinary & $\begin{array}{l}\text { Multidisciplinary } \\
\text { although surgeons } \\
\text { accounting for } \\
\text { majority }\end{array}$ & $\begin{array}{l}\text { Mainly paramedics and } \\
\text { clinical team mentors } \\
\text { (CTMs) attended }\end{array}$ \\
& & & $\begin{array}{l}\text { workshops. } \\
\text { Strategic Innovation } \\
\text { Programmes Manager } \\
\text { (project champion) was } \\
\text { also involved, but } \\
\text { unfortunately did not }\end{array}$ \\
& & & \\
\hline
\end{tabular}




\begin{tabular}{|c|c|c|c|}
\hline & & & attend the workshops. \\
\hline $\begin{array}{l}\text { Simulation } \\
\text { Study } \\
\text { objectives }\end{array}$ & $\begin{array}{l}\text { To explore: } \\
\text { - } \quad \text { reducing the } \\
\text { waiting list for a } \\
\text { number of clinics in } \\
\text { the pathway } \\
\text { - reducing the } \\
\text { number of beds } \\
\text { required in post op } \\
\text { care } \\
\text { the achievement } \\
\text { of the } 18 \text { week } \\
\text { target for referrals }\end{array}$ & $\begin{array}{l}\text { - To understand the } \\
\text { patient pathway } \\
\text { - To explore } \\
\text { reducing patient } \\
\text { throughput time }\end{array}$ & $\begin{array}{l}\text { To identify ways to } \\
\text { improve the efficiency } \\
\text { of the ambulance } \\
\text { service call cycle by } \\
\text { increasing the } \\
\text { percentage of: } \\
\text { - Hear and Treat calls } \\
\text { - Sea \& Treat cases } \\
\text { - cases conveyed to } \\
\text { Alternative care } \\
\text { providers }\end{array}$ \\
\hline $\begin{array}{l}\text { workshop } \\
\text { involvement }\end{array}$ & $\begin{array}{l}4 \text { workshops (average } \\
\text { duration } 2 \text { hours) } \\
\text { Most meetings took place } \\
\text { in a hospital meeting } \\
\text { room }\end{array}$ & $\begin{array}{l}4 \text { workshops } \\
\text { (average duration } 2 \\
\text { hours) } \\
\text { Most meetings took } \\
\text { place in external } \\
\text { conference room }\end{array}$ & $\begin{array}{l}4 \text { workshops (average } \\
\text { duration } 2.5 \mathrm{hrs} \text { ) } \\
\text { Most meetings took place } \\
\text { in a seminar room at } \\
\text { Loughborough University. }\end{array}$ \\
\hline $\begin{array}{l}\text { Action resulting } \\
\text { from study }\end{array}$ & $\begin{array}{l}\text { More operating slots and } \\
\text { decision to build new } \\
\text { obesity surgery operating } \\
\text { theatre }\end{array}$ & $\begin{array}{l}\text { Decision to introduce a } \\
\text { new process in the } \\
\text { care pathway }\end{array}$ & $\begin{array}{l}\text { Agreement that the service } \\
\text { should increase } \\
\text { involvement of the clinical } \\
\text { assessment team in the call } \\
\text { cycle to provide advice } \\
\text { over the phone. }\end{array}$ \\
\hline
\end{tabular}

In all three studies stakeholders engaged well with the process and the tools used as part of the workshops, interacting either with the facilitators or each other. The stakeholder team participating in the workshops of the three studies was different. In the obesity study the group comprised of many different specialties. The divergence is less in the colorectal study and far less in the AS study where only front end staff that went out in ambulance calls attended the workshops. Their managers were reluctant to attend the workshops as they were worried this would affect the free expression of views among their staff. Despite the efforts of the modelling team to include also members outside the organization, such as clinical staff from the associated emergency departments in interconnected hospitals, this was not considered suitable from the AS management for confidentiality purposes, hence not pursued. Contrary to the first two applications the project champion in the AS study was not able to attend any of the workshops, which meant that the support experienced in the previous two studies during the workshops was not present. Despite not having attended any of the workshops, the AS study project champion supported the study and the modeller fully throughout.

Considering, the conversations that took place in the workshops, participants were fully involved and contributed enthusiastically in all the tasks when invited. It is observed that there were more heated 


\section{Tako and Kotiadis}

discussions among the participants of the obesity study than the colorectal and the AS study. This is likely to be related to the consistency of the group of participants, which included managers (non-clinicians) and nurses with more differences in their experience of the system and therefore their thinking. However, all arguments were resolved within the workshop and in all three studies the stakeholders gave equal praise to the modelling team about the overall experience and the knowledge gained as a result of these workshops.

All three studies reached to a consensus about the action to be taken as a result of discussions taking place within the workshops, however the level of implementation differs between the different studies. In the first two studies, the project champion met with other stakeholders outside of the workshops in an effort to push forward action. In both cases this took place between the third and the fourth workshop. The modelling team was not aware of these meetings until the fourth workshop. This turn of events was surprising to the modelling team, we however believe that the project champions, which in both cases were powerful and influential, were motivated by the knowledge gained and discussions conducted during the experimentation workshop. On the contrary, the project champion, filled in by the strategic innovation programs manager in the AS study, was not able to attend any of the workshops. He was however equally supportive of the study outside the workshops, who met with the modeller to discuss data input needs, validate the model and propose scenarios. After having read the stakeholder report post workshop 3, he/she was very enthusiastic about the findings and as a result arranged for the modelling team to present the results of the study to the Board of Directors of the AS trust. Despite the results being received enthusiastically by the service and its management team, the year after (2017) a re-organisation of the call cycle and the way time targets are counted throughout the service was centrally introduced. This change meant that it took away the attention of the service from the simulation study, hence we are not clear about the outcomes of the study, however the modelling team is aware that the AS continues to make use of the clinical assessment team to provide hear \& treat care to patients. Hence we can conclude that the outcomes of all three studies were positive and that the process undertaken and discussions that took place at the workshops played an important role in generating ideas and reaching consensus, which may have not been possible if we were to speak to stakeholders individually. We next provide some examples of tools used in PartiSim workshops.

\section{EXAMPLE TOOLS}

This section provides some examples of tools used in PartiSim stakeholder-oriented workshops to give the reader a feel of the process followed and the facilitation at the workshops. We choose three tools, draw a system model (part of Workshop 1), rating the performance measures (part of workshop 3) and Analyzing risks and feasibility of change (part of workshop 4) to give the reader an insight of how they work in practice.

\subsection{Draw a system model}

The system model consists of a graphical representation of the key activities occurring in the system of interest. It is completed as part of the third and last activity in workshop 1 (Define the conceptual model), after the problem statement activity and define the system with the stakeholders takes place. The Draw the System Model Tool (Figure 1) and manual can be utilised, which consists of paper-based tools that stakeholders complete during the workshop with the facilitator's support.

The process of developing a System Model consists of collecting the verbs that describe the activities that take place in the care system, based on the logical dependencies involved (Checkland and Scholes, 1999). We group the key activities that take place in healthcare systems, into three generic categories: clinical/operational, managerial and research. The clinical/operational part can be a closer representation to the computer model, depending on the problem situation studied (Kotiadis and Robinson, 2008). Whereas, the research and managerial parts are considered useful in order to enrich the understanding of the operational (clinical in health care settings) needs leading to a better model. The facilitator can find 


\section{Tako and Kotiadis}

guidance and tips in the accompanying manual for this tool, such as questions to be directed to the participants while using the tools. The process of designing the Care System Model (CSM) with the stakeholders helps to gain further insights about the problem situation by both stakeholders and the modelling team.

An example of the tool completed at the workshop for the obesity study is presented in Figure 1. This exercise served as means of bringing out some additional problems and inefficiencies involved in their obesity system that had not emerged during the problem statement activity. Concerns were raised regarding inefficiencies present in the care system such as patients wrongly being referred to some clinics resulting in long waiting lists. Stakeholders were then asked to identify interrelations between the three groups of activities (managerial, clinical and research). For example, the managerial activity "Design and set up patient group forum" is connected to the clinical activity "Provide group forum for patients" in Figure 1.

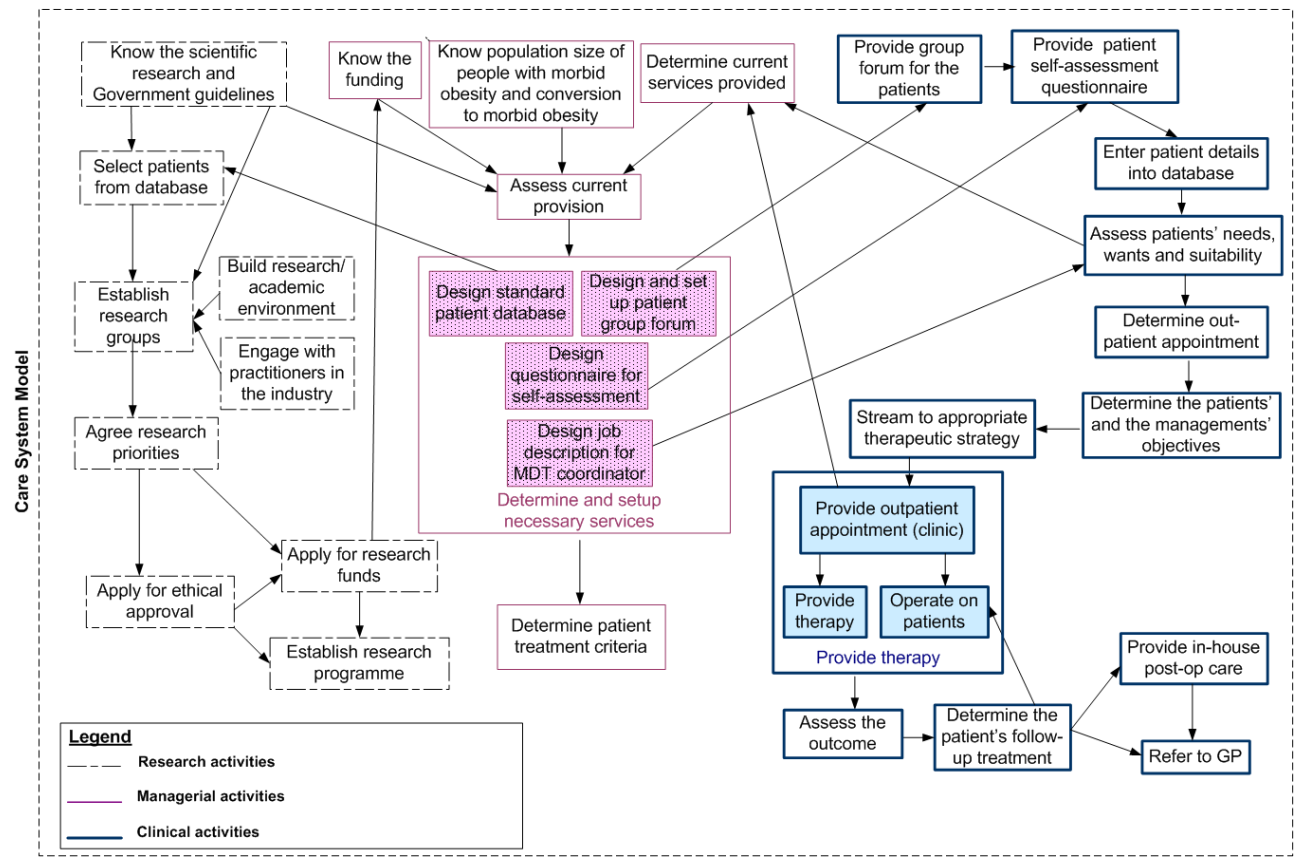

Figure 1: A System Model representing the research, managerial and clinical activities in the obesity care system

\subsection{Rating the performance measures}

Rating the performance measures is the second activity in workshop 3 (Experimentation stage, Table 1). Performance measures are the key model outputs. The aim of this activity is to get the stakeholders to focus on the most important measures (model outputs), which are then subsequently used to ultimately narrow the solution space of the scenarios. They have been initially identified in workshop 2 as part of defining the conceptual model. After the simulation model is developed, it is brought to Workshop 3 for the stakeholders to validate, including the model outputs. In this activity, the participants are guided through a process to identify and negotiate the importance attached to each performance measure.

The activity is guided by the Rating the Performance Measures Tool and its manual (Column 2, Table 1). This tool is based on multi-criteria decision analysis (MCDA) (Belton and Stewart 2002). It is available as paper-based tool and as a software tool, such as VISA software (http://www.visadecisions.com), for which one needs to have a license. This tool consists of a value tree representing model results (performance measures) and the weight in terms of importance attached to each one by the stakeholders. An example of a value tree developed for the obesity study (Table 2), using 


\section{Tako and Kotiadis}

the VISA software is presented in Figure 2. In this case, the value tree was set up prior to the workshop using the performance measures that were identified in the previous workshop (workshop 2) and during model coding. It should be noted that the modelling team had only recently started to learn and use VISA and to avoid any unexpected technical hitches and subsequent delays, prepared printouts of VISA outputs in advance. Nevertheless, the VISA software has the potential to be used live, if the modelling team is familiar with using it. The benefit of using VISA live in the workshop lies in that the results of different scenarios, can be connected with the agreed value tree in order to evaluate each scenario and to identify the most desirable and feasible scenario/(s). This is because the VISA software is compatible with the simulation software we used (www.simul8.com) to develop the DES model. It is also possible to rate the performance measures using the paper-based tool, without the VISA software and/or anonymously, as explained in the PartiSim User Guide and Toolkit (Kotiadis and Tako 2010). In the subsequent two studies (Colorectal and Ambulance service) the paper-based tool was used instead, in the former for the purpose of trialing the tool and the latter because the modeller did not have access to the VISA software.

At the workshop in the obesity study, the facilitator started the activity by asking the stakeholders to express their opinions about the importance of each performance measure, by weighing each one on a scale from zero to one hundred (Figure 2). During the validation part of the workshop, it had already become clear that the waiting lists were of high importance to all stakeholders, especially for the pharmacology and surgery clinics. The stakeholders on the whole agreed with the weights assigned prior to the workshop (Figure 2) so no changes were needed. Subsequently, the stakeholders moved on to the next workshop activity to debate desirable and feasible scenarios based on the performance of the scenarios of interest for the most important outputs.

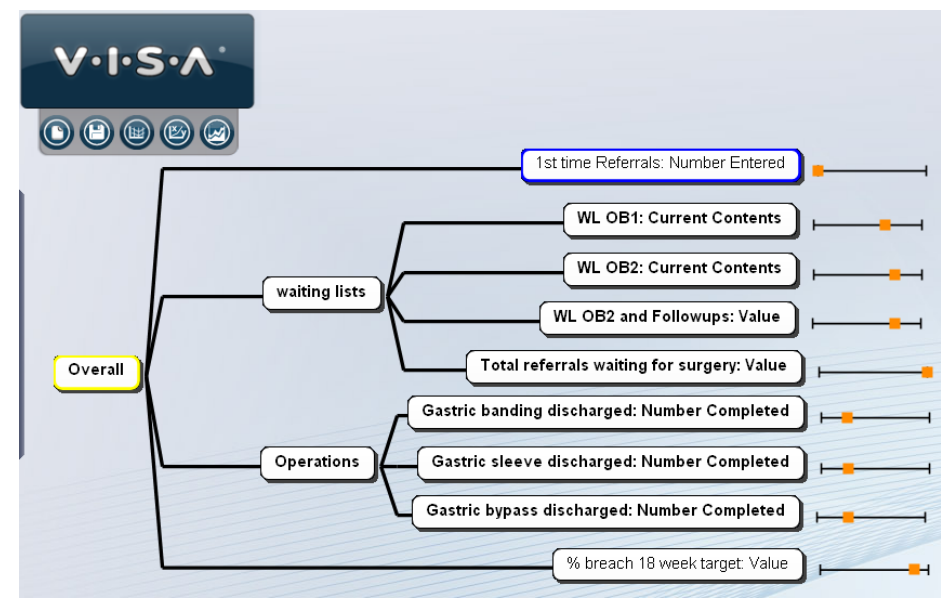

Figure 2: Value tree rating performance measures of the obesity system using VISA software

\subsection{Analysing risks and feasibility of change}

Analysing risks and feasibility of change is the second activity in Workshop 4 (Implementation Stage), after a discussion where the learning and changes that may have been introduced so far is reviewed. This workshop activity focusses on the scenario identified as most desirable, based on it achieving the highest performance for the most important performance measures (model outputs). The Feasibility and Risks Scale Tool is used and the aim is to narrow the solution space to ideally one scenario that could be implemented, by identifying the factors that may hinder implementing the changes linked to the chosen scenario, with the view to weighing up the feasibility of the scenarios chosen. It is recognised that factors such as psychological perceptions may hinder the stakeholders from taking action (Ajzen 1991).

At the workshop in the obesity study, out of the six scenarios explored the third scenario was the best performing for most performance measures. This was also the most preferred scenario by all stakeholders. 


\section{Tako and Kotiadis}

The facilitator started this activity by asking the stakeholders to consider how this scenario could be put in place and hence the inhibiting factors were discussed.). The Feasibility and Risks Scale Tool (Figure 3) and its manual are used to identify the reasons for which this scenario was feasible and the reasons for which it was not feasible. All stakeholders were encouraged to contribute to the discussion. The facilitator put forward two columns, one for reasons supporting the feasibility of the scenario and the other for reasons against it and recorded on a flipchart. The points made were listed and the scale was constructed by drawing a sloping line, dipping in this case on the not feasible side of the scale.

As a result of this process, Scenario 3 was deemed to be not feasible in the short term because of the timescale of adding new resources in the real system. In the real life system, a delay of a few months in introducing the additional resources would not guarantee its results. As the admissions and waiting lists in the real system would be increasing it would take longer to reach equilibrium in the system, where key targets are not breached. An example of the discussion that took place at the workshop is shown below, where physical space was identified as an issue for implementation of the scenario:

Stakeholder A: I don't think this is working. I think this system internally, for us, having a third surgeon here, the third surgeon, the issue is not really physically, in terms of surgery, it's a case of space.

Stakeholder B: Beds and space.

Project Champion: We've assumed the space will just magically appear.

$<$ Laughter $>$

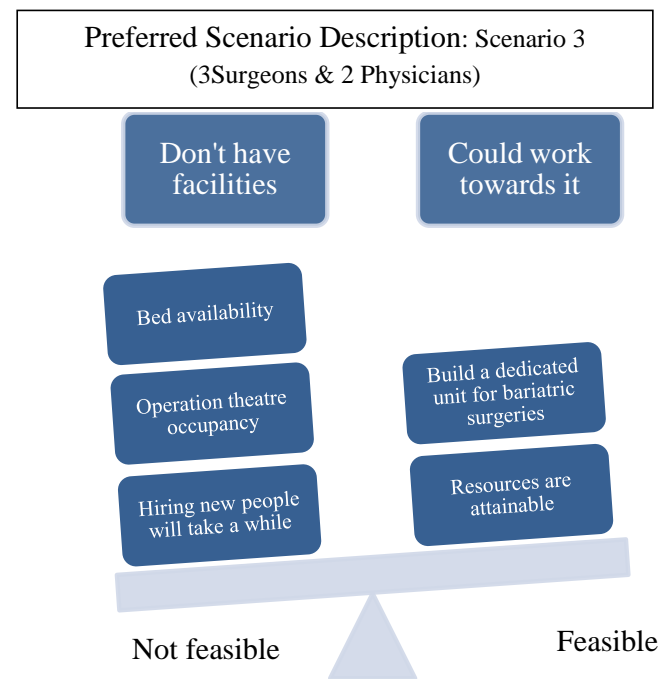

Figure 3: Example of using the feasibility and risk scale Tool to analyse a scenario

As a result of this analysis, it was accepted that scenario 3 was not feasible mainly due to timing issues. A number of other scenarios was discussed till a scenario considered feasible by the group was identified, before moving on to the next workshop activity.

We next provide a roadmap of the journey that potential users interested in adopting PartiSim in their project should be undertaking.

\section{ROADMAP TO ADOPTING PARTISIM}

In this section we explore the process of adopting PartiSim and of undertaking a facilitated modelling mode in a DES modelling project. This guidance alongside the PartiSim materials freely available will 


\section{Tako and Kotiadis}

support a modeller or a modelling team to change their practice from an expert to facilitated mode of DES practice. The adoption of PartiSim can be considered at two levels: the individual and the team level. This means that effort is required from individuals within a team, as well as the whole team, in order to become competent in undertaking PartiSim as part of an intervention. We next consider each level separately.

The individual level training can be undertaken by members of the modelling team such as those taking on the role of a workshop facilitator or simulation modeller. It is advised that all those in the modelling team embark on this individual development prior to coming together as a team. This could be considered as an ongoing 4-stage loop (left loop, Figure 4) with each iteration making the individual reflect on their knowledge and experience and thus taking on a continuous improvement plan at a personal level. The questions asked should include: "What did I do well?" and "What should I have done differently to engage clients?"

In our experience of PartiSim we have found that in each intervention we have gained experience and enlightenment leading to better practice in subsequent case studies. Moving from expert mode to facilitated mode is an ongoing journey of personal development. Hence the loop starts and ends at the same point, with reflection (left loop, Figure 4). At the personal level the individual should engage with the framework and tools prior to each intervention in order to familiarise him/herself with the content taking into account all the updates to practice. Indeed the development of the PartiSim website by the authors is aimed at providing a knowledge base of up-to-date practice and all teams engaging in PartiSim are encouraged to contribute to its ongoing refinement and development.

We acknowledge that workshop facilitation is an art that requires ongoing refinement and individuals looking to take facilitation roles are encouraged to update their competencies though reading or practice on an ongoing basis (see bottom activity of left loop, Figure 4). The art of facilitation extends beyond simulation (Robinson 2014, Tako and Kotiadis 2015) and OR (Franco and Montibeller 2010, Taket 2002, Ackermann 1996) to other fields (Kaner 2007) and is constantly evolving. The DES community has a lot to learn from the research into facilitation led by the Problem Structuring Community (also known as soft OR community largely based in the UK and Europe) in OR. Other areas that should also be considered is that of behavioural OR, a newcomer to the field, that concerns itself with how groups interact with models and the modelling process, providing research and understanding that could feed into the facilitated and participative DES practice (Franco and Hamalainen 2016). Following on from updating and developing competencies the individual is encouraged to take part in an actual intervention. At that stage one enters the next 5-stage loop, the PartiSim team development (right loop, Figure 4), with "Apply PartiSim to real case study". This is discussed in more detail in the next paragraph. The point made here is that one cannot be fully proficient in PartiSim unless they engage in real practice. The first time an individual undertakes the loop, he/she should be encouraged to consider their journey as a learning experience where improvements and adjustments will be necessary in future applications. 


\section{Tako and Kotiadis}

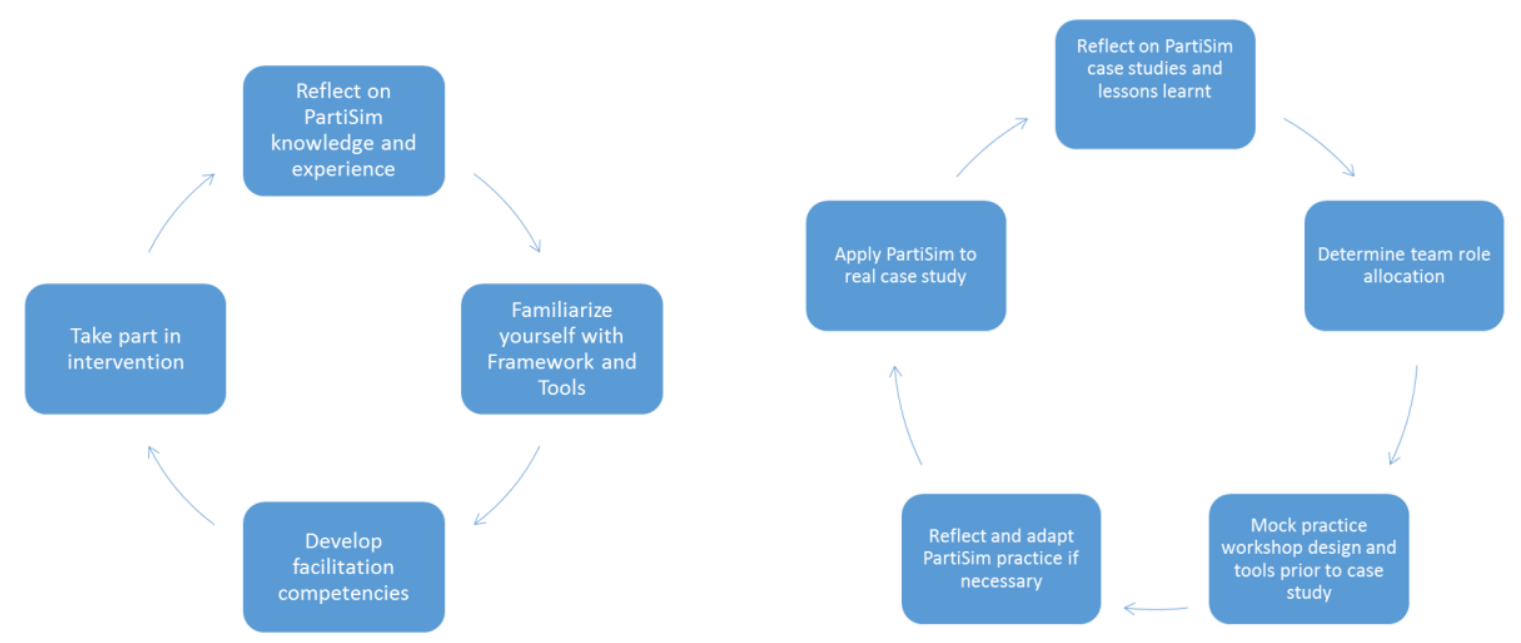

Figure 4: Personal (left) and team (right) development for adopting PartiSim in DES interventions

Now we consider the process that could be followed by a team adopting PartiSim (right loop, Figure 4). Similarly to an individual's development journey towards PartiSim it is advised that a team is formed at the beginning of any intervention. In the very first loop the modelling team should hold a PartiSim awareness event where existing literature is discussed and any concerns and issues are raised with a view that all the team have a good initial grasp of the process, guidance and tools before commencing practice. At this point it could be that some individuals within a team commence their personal journey (left loop, Figure 4) although it would be better if that has taken place to some extent before the team meet.

The PartiSim framework identifies the roles that will enable the delivery of the simulation study, from both the stakeholder and modelling team, to include roles such as the facilitator, modeller and recorder, but also key stakeholders, project initiator and project champion (Kotiadis et al 2014). The project champion comes from the stakeholder team; he/she has good communication and interpersonal skills to create awareness, confidence and consensus, but has also authority and influence within the organization to build up commitment to the project. At the end of the study, they can in turn support and ensure the delivery of implementation plans agreed at the end of the study. Ideally we would suggest that the modelling team embarking on a change in practice should have at least one stakeholder (ideally the project champion) involved in this early reflection stage in order to get feedback on the process. Having familiarised themselves with PartiSim, the modelling team should discuss the roles that they are prepared to trial in the first loop. Modellers that are confident communicators should consider developing their skills in facilitation but equally if the skillset is not currently present within a team additional members, possibly outside of DES modelling, could be sought. Obviously, at this point, it is expected that a prospective intervention has been already identified and the team would be preparing for the first workshop. In our experience we found that holding mock practice workshops without the actual stakeholders (the modelling team and/or other externals to the intervention acting as stakeholders) helped improve the flow of the actual workshop. For example, at this stage an experienced facilitator should engineer opportunities for others in the team to trial facilitation in small time chunks (e.g. 30 minutes) as part of the team's training and development.

Having embarked on mock workshops the modelling team should hold a debriefing to reflect on the workshop process, flow and duration with the view of adapting practice to their strengths for the real application. The allocation of roles and development of competencies within the modelling team, should also be reconsidered. Following this, the modelling team should be ready to engage in a real application. At the end of the intervention a meeting should be held by the modelling team to reflect on workshops, roles and competency development with a view to improving practice in the subsequent loop/application. Given that modelling team membership may deviate from one intervention to another it is advised that 


\section{Tako and Kotiadis}

modelling teams consider the loop for PartiSim team development (right hand loop, Figure 4) for each application. PartiSim is just as much about the collaborative approach within the modelling team as it is between the modelling team and the stakeholder team during the intervention.

\section{PRACTICAL TIPS FOR USING PARTISIM}

We conclude the tutorial with some additional practical tips for using the PartiSim approach and its tools for potential adopters of the approach to consider, as listed below:

- Identify from the outset of the study whether the stakeholder team are willing and/or need to be involved in the study. If dealing with a complex problem, where people in the system hold different opinions and contradicting views about the problem, with little communication amongst teams, a participative study would be suitable.

- It is beneficial that the membership of the stakeholder team is consistent throughout the study to ensure that there is continuity in the outputs and learning from one workshop to the other. For this reason an agreement from the beginning of the study should be made with participants to commit to attending all four workshops and dates agreed in advance if at all possible. A good way to incentivize good participation is to create a good rapport with the stakeholder group and to offer opportunities for informal chats at breakouts, i.e. coffee/lunch breaks.

- Being flexible and willing to accommodate stakeholder requirements. In all three studies discussed in section 3, we have found that working with clinicians and healthcare staff, with high risk responsibilities and busy schedules we have had to make a conscious effort to keep workshops duration as short as possible and accommodate workshops around stakeholders' commitments. Some examples include being flexible on the start time (e.g. $7 \mathrm{am})$ and location (e.g. hospital meeting room) of workshops to suit stakeholders' busy schedules.

- Besides keeping workshops as short as possible, ideally approximately two hours, we also recommend leaving time between workshops, between 2-4 weeks to give time to the modelling team to summarize workshop outputs, prepare for the next workshop, collect data or information required for the model, etc. This time is also beneficial for the stakeholder team to let ideas sink in and come up with fresh ideas in subsequent workshops.

- From the modeller's perspective, being able to apply the PartiSim approach effectively, one needs to be prepared and open to deploying a multi-paradigm approach, meaning moving between the soft and hard paradigms between the different activities (Tako and Kotiadis, 2015). For novice modelers or those more familiar with the hard paradigm, this can mean being consumed by the model and its results rather than focusing on the client interaction and the process (a framework, its stages and outputs). More details about how each paradigm is deployed at each PartiSim stage is provided in Tako and Kotiadis (2015). It is beneficial to be familiar with Soft Systems Methodology (SSM) (Checkland 1999) and more generally the problem structuring field.

DES modellers and analysts are invited to carry out a PartiSim study in their simulation projects and reflect on the facilitation skills needed to develop. We believe that using the overall framework and tools is especially useful for novice modellers and those looking to develop their facilitation skills by undertaking the journey described in the roadmap (section 5). The PartiSim materials, user guide, tools

and manuals are available for interested modellers to access for free from our website (www.partisim.org).

\section{REFERENCES}

Ackermann F (1996). Participant's perceptions on the role of facilitators using group decision support systems. Group Decision and Negotiation 5 (1): 93-112. 
Ajzen, I. (1991). "The theory of planned behaviour." Organisational Behaviour and Human Decision Processes 50: 179-211.

Belton, V. and T. J. Stewart (2002). Multiple criteria decision analysis: an integrated approach. Dordrecht, Kluwer.

Checkland, P. (1999). Systems thinking systems practice. Chichester, Wiley.

Checkland P and Scholes J (1999). Soft Systems Methodology in Action. Wiley. Chichester. UK.

Franco, L. and Hamalainen, R., 2015. Behavioural operational research: returning to the roots of the OR profession. European Journal of Operational Research, 249(3), pp. 791-795.

Franco, L. and G. Montibeller (2010). "Facilitated modelling in operational research." European Journal of Operational Research 205: 489-500.

Kaner S (2007). Facilitator's Guide to Particpatory Decision Making. San Francisco, CA, Jossey-Bass.

Kotiadis K and Tako AA (2018) Post-model coding facilitation in DES: A case study in Healthcare. European Journal of Operational Research.

Kotiadis K and Tako AA (2010) PartiSim User Guide to Facilitation Version 1 (December 2010), DOI: 10.13140/RG.2.1.3659.1201

Kotiadis K, Tako A, Vasilakis C, (2014) 'Participative and Facilitative Conceptual Modelling'. Journal of the Operational Research Society, 65 (2), 197-213.

Phillips C. (2017) 'Participative simulation and collaborative model design used to manage uncertainty and align production with demand', Working paper, Bangor University

Proudlove, N, Bisogno, S, Onggo, BSS, Calabrese, A \& Levialdi-Ghiron, N 2017, 'Towards fullyfacilitated discrete event simulation modelling: Addressing the model coding stage' European Journal of Operational Research, vol 263, no. 2, pp. 583-595.

Puntambekar N. (2016) Exploring the efficiency of a UK ambulance service through Discrete-Event Simulation, Master Dissertation, Loughborough University.

Robinson, S., Worthington, C., Burgess, N. and Radnor, Z.J. (2014). Facilitated modelling with discreteevent simulation: Reality or myth? European Journal of Operational Research, 234 (1): 231-240.

Tako AA, Kotiadis K, (2015) 'PartiSim: A Framework for participative simulation modelling'. European Journal of Operational Research, 244(2), p555-564.

Tako AA, Kotiadis K, Vasilakis C, Miras A, le Roux C W, (2014) 'Modeling patient waiting times for an sobesity service: a computer simulation study'. BMJ Quality and Safety, 23 (5) p373-381.

Taket, A. (2002). "Facilitation: some contributions to theorising the practice of operational research." Journal of the Operational Research Society 53(2): 126-136.

\section{AUTHOR BIOGRAPHIES}

ANTUELA A. TAKO is a Reader in Operational Research at the School of Business and Economics, Loughborough University. She holds a PhD in Simulation and an MSc in Management Science and Operational Research from the University of Warwick. Her research interests include the comparison of simulation approaches (discrete-event simulation and system dynamics), facilitated and participative simulation modelling, conceptual modelling and health care modelling. She is Associate Editor of the Journal of the Operational Research Society. Her email address is a.a.takou@lboro.ac.uk and her webpage is: http://www.lboro.ac.uk/departments/sbe/staff/anthi-antuela-tako/.

KATHY KOTIADIS is Kathy Kotiadis is a Reader (Associate Professor) in Management Science/Operational Research at the Kent Business School, University of Kent. She graduated with a $\mathrm{BSc}$ (Hons) in Management Science and went on to do a $\mathrm{PhD}$ in Operational Research at the University of Kent. Her main research interests include discrete event simulation modelling applied to health care and the development of the simulation methodology through Problem Structuring Methods. In 2009 she was awarded the KD Tocher Medal by the OR society for the best simulation paper published in the Journal of Simulation over the period 2007-8. Her email address is K.Kotiadis@ kent.ac.uk. 